\title{
A TRAJETÓRIA RECENTE DA EDUCAÇÁO DE PESSOAS JOVENS E ADULTAS NO CHILE: INFERÊNCIAS DE UM ESTUDO COMPARADO
}

\author{
THE RECENT TRAJECTORY OF EDUCATION OF YOUNG AND ADULT \\ PEOPLE IN CHILE: INFERENCE FROM A COMPARATIVE STUDY
}

\author{
Adenilson Souza Cunha Júnior \\ Doutor em Educaçáo pela Universidade Federal de Minas Gerais. \\ Professor do Programa de Pós-Graduaçáo em Educação da Universidade Es- \\ tadual do Sudoeste da Bahia, Vitória da Conquista, BA - Brasil. \\ ORCID: https://orcid.org/0000-0003-3622-1799 \\ adenilsoncunha@uesb.edu.br
}

Leôncio José Gomes Soares

Doutor em Educação pela Universidade de São Paulo. Professor do Programa de Pós-Graduação em Educação da Universidade Federal de Minas Gerais, Belo Horizonte, MG - Brasil.

ORCID: https://orcid.org/0000-0003-4750-2529 lenciogsoares@gmail.com

Violeta Rosa Acuña Collado Doutora em Educaçáo pela Universidade Católica do Sagrado Coraçáo de Miláo, Itália. Professora do Programa de Pós-graduação em Educação de Adultos e Processos Formativos da Universidad de Playa Ancha, Valparaíso - Chile. ORCID: https://orcid.org/0000-0001-7544-8828

Resumo: Este artigo é um recorte de uma pesquisa mais abrangente defendida como tese no curso de doutorado latino-americano em educação, políticas públicas e profissão docente da Universidade Federal de Minas Gerais intitulada: Formação de professores para a Educação de Pessoas Jovens e Adultas (EPJA), no Brasil e no Chile: Um estudo comparado entre a Regiáo de Valparaíso e o Estado da Bahia. Neste texto, nos limitamos em apresentar os dados que foram produzidos no período de estágio doutoral realizado no Chile. Considerando que a pesquisa acadêmica sobre a EPJA nesse país é incipiente e mantém uma relação direta com a pouca relevância que tem sido dada a essa modalidade enquanto política pública, o estudo em tela possibilitou coletar e sistematizar dados para análise, interpretação e comparação a partir da perspectiva metodológica da educação comparada, numa abordagem panorâmica sobre a trajetória recente da EPJA no país quanto a suas concepçóes, finalidades e inserção no âmbito da política educacional chilena. Evidenciamos que a perspectiva certificadora da EPJA no Chile acompanha as bases ideológicas da política neoliberal assumida pelo Estado, levando a crer que a 
modalidade deve cumprir apenas com a finalidade de integrar seus sujeitos ao mundo do trabalho e garantir a empregabilidade.

Palavras-chave: Educação Comparada. Educação de Pessoas Jovens e Adultas. Política Educacional.

Aвstract: This article is a fragment of a larger study on Teacher Training for Education of Youth and Adults (EPJA) in Brazil and Chile: A Comparative Study between the Region of Valparaiso and the State of Bahia, defended as a thesis in the course of a Latin American doctorate in education, public policies and teaching preffesorship of the Federal University of Minas Gerais. In this text, we limit ourselves to presenting the data that we produced during the doctoral training period. Considering that academic research on EPJA in Chile is incipiente and maintains a direct relationship with the low relevance that this modality of education has been treated as State Policy, the study made it possible to systematize the information that was submitted for analysis, interpretation and comparison from the methodological perspective of comparative education, making it possible to present a panoramic approach on the recent trajectory of EPJA in the country, reflecting on its conception, purpose and insertion within the framework of its educational policy. We show that the certification perspective of the EPJA in Chile follows the ideological bases of the neoliberal politics assumed by the State, leading to the belief that the modality should comply only with the purpose of integrating its subjects into the world of work and guarantee employability.

Keywords: Comparative Education. Education of Youth and Adults. Educational Politics.

\section{Introduçáo}

Apesar da trajetória histórica percorrida na tentativa de ampliar seu reconhecimento e legitimação, a Educação de Pessoas Jovens e Adultas (EPJA), enquanto modalidade de oferta educativa, continua no conjunto das políticas oficiais dos governos latino-americanos ocupando lugar secundário, excluído, marginalizado, seja pela limitaçáo do acesso à escola seja pela inadequação das propostas, ou pela ausência de políticas públicas de financiamento e formação de professores para atuar nesse segmento da educação.

Amplas pesquisas desenvolvidas pela Organização das Naçôes Unidas para a Educação, a Ciência e a Cultura (UNESCO) e informadas através do Relatório Global sobre Aprendizagem e Educação de Adultos (UNESCO-GRALE I, 2010; UNESCO-GRALE II, 2012), além do monitoramento realizado por organismos regionais, a exemplo do Centro de Cooperación Regional Para La Educación de Adultos en América Latina y 
El Caribe (CREFAL) e o Conselho de Educação de Adultos da América Latina (CEAAL), apresentam uma visão restrita sobre a EPJA nos países da regiáo ${ }^{1}$, quase sempre atrelada às políticas educacionais subsidiadas pelos programas de pobreza e reduzida às generosas concepçóes e metas originais das políticas focalizadas na instrução primária de crianças, confinando a modalidade a uma posição marginal na agenda pública. (TORRES, 2001, 2003).

Esse entendimento reflete, com efeito, as reformas do Estado e a implantação das políticas neoliberais dos anos 1990, com intensa participação de organismos internacionais, em especial o Banco Mundial, que tiveram repercussóes sistemáticas para o entendimento da educação como política social, para a implementação de novas regulaçôes da educação e do trabalho docente e, consequentemente, para definir sua funçáo na reestruturação produtiva a serviço do modelo econômico que se implantou na regiấo. Se, por um lado, tais reformas suscitaram a importância da EPJA para o desenvolvimento econômico e social das naçóes, por outro não a colocou entre as prioridades de financiamento no âmbito da escola básica, mantendo-a centrada na alfabetização inicial e não na educação básica em seu sentido amplo (DI PIERRO; JOIA; RIBEIRO, 2001), o que reforçou seu caráter compensatório.

Dez anos após amplo estudo realizado por Di Pierro (2008), é possível verificar que essa tendência continua presente, ficando de fora apenas os países que deram maior grau de institucionalidade à EPJA, dotando a modalidade de recursos específicos, autonomia e prestígio e, dessa forma, conduzindo-a a obter bons resultados em termos práticos, como maior oferta de matrícula, melhores condiçóes para formação de professores e, por conta disso, melhor qualidade de ensino. Na atualidade, percebe-se que maior parte dos governos latino-americanos continuam levando adiante políticas similares àquelas que se deram na década de 1990. Apenas alguns países da região como Brasil e Chile rechaçaram - pelo menos discursivamente - essa perspectiva e procuram recuperar o protagonismo estatal para a oferta educativa às populaçóes jovens e adultas.

Dessa maneira, os contextos de inserção da EPJA nas políticas e nos sistemas oficiais de ensino dos países da região apresentam relação direta com a diversidade de oferta da modalidade educativa e os requisitos necessários para o trabalho com seus destinatários. Visto que, na medida em que 
a modalidade é reconhecida e possui aportes para o seu desenvolvimento, melhores são as condiçôes para sua execução, cabe uma compreensão mais ampla desse campo da educação.

Neste texto, recorte de uma pesquisa mais abrangente intitulada Formação de professores para a educação de pessoas jovens e adultas no Brasil e no Chile: um estudo comparado entre a regiáo de Valparaíso e o estado da Bahia, defendida como tese no curso de doutorado latino-americano em educação da Universidade Federal de Minas Gerais, apresentamos algumas inferências sobre os dados que foram coletados no período de realização do estágio doutoral no Chile.

A construção metodológica deste estudo, a educaçáo comparada, se alicerça no pressuposto de que "a pesquisa comparativa interpreta e constrói fatos, não se limitando a descrevê-los.” (NÓVOA, 1995, p. 61, tradução nossa) Para cumprir essa finalidade, fez-se necessário elaborar procedimentos que serviram de base à interpretação, ou seja, "una idea guía preliminar a partir de la cual se deben tratar los datos que han de ser comparados.” (MARQUÉZ, 1972, p. 143) Assim, nos orientamos pela perspectiva de Bereday (1972), elencando três etapas para desenvolvimento e operacionalização da comparação: a descrição dos fenômenos, a explicação e a comparação.

No momento da descrição, fase inicial da pesquisa, foram definidas a utilização das fontes. Esse momento consistiu em "la colección sistemática de informaciones para la descripción de los sistemas y de las prácticas educativas." (BEREDAY, 1972, p. 11). Para a realização desse procedimento, recorremos a uma análise minuciosa e detalhada de documentos, informes, relatórios e demais dados institucionais produzidos pelo governo chileno, assim como entrevista semiestruturada com a coordenadora nacional de educação de adultos do Ministério da Educação do país. As perguntas que foram sistematizadas para entrevista objetivaram complementar lacunas e limitaçóes das informaçôes contidas nesses documentos como: concepção institucional de EPJA, ambientação das políticas públicas para a modalidade na agenda do Estado, financiamento e formação de professores para essa área da educação no Chile.

A partir da organizaçáo dos dados, apresentamos aqui "o estudo das realidades nacionais [neste recorte, o Chile] a partir de uma perspectiva analítica e explicativa", (KRAWCZYK; VIEIRA, 2006, p. 675), ou expli- 
cativa/comparativa, elementos subsequentes à fase descritiva da pesquisa. permite-nos adensar os debates sobre a trajetória recente da EPJA no país e refletir sobre suas concepçóes, finalidades e inserção no âmbito da política educacional chilena.

\section{A trajetória recente da Educação de Pessoas Jovens e Adultas no Chile}

As transformaçóes socioeconômicas que o Chile atravessou nas últimas décadas do século passado, marcadamente tributárias da perspectiva neoliberal e compromissadas com a reforma do Estado, alteraram significativamente as políticas educacionais e a estruturação do sistema de ensino do país, que "seguiu de forma sistemática as diretrizes das reformas educacionais que foram orientadas por organismos multilaterais, como o Banco Mundial, OCDE etc." (SCHNEIDER, 2015, p. 78). Objetivavam tais políticas, sob a égide da descentralização, melhor ajuste fiscal e, consequentemente, melhor desenvolvimento econômico do setor produtivo. No escopo das diretrizes estava, conforme assinala Brito (2001, p. 157), "a revisão do papel do Estado na educação, deixando de ser o principal executor e passando a constituir uma instância coordenadora e controladora”.

Até os anos 1980, o Ministério da Educação centralizava todas as responsabilidades políticas, pedagógicas e administrativas, tais como o pagamento e a contratação de professores. Em meados dessa década, as políticas de descentralização delegaram aos municípios a gestão da educaçáo. Nesse ordenamento, iniciou-se o processo de financiamento da escola pública por meio de subvenção ${ }^{2}$ e instaurou-se o sistema de vouchers $^{3}$, com investimentos públicos na educação privada. Casassus (2001) defende que o Chile, no âmbito das políticas orientadas para a regiáo, colocou a educação no centro das prioridades de desenvolvimento, situando-a como um setor estratégico para inserção do país no processo de globalização.

Dessa forma, a consolidação do projeto educativo chileno vem, ao longo dos anos, se processando sob a lógica da internacionalização da economia e do mercado e na formação de capital humano, embora os governos tentem rechaçar, ao menos discursivamente, a ideia de que a educação 
no país se destine a aspectos mais amplos de formação dos indivíduos. Nas palavras de Corvalán (2008, p. 31):

El concepto de capital humano que se viene utilizando crecientemente en torno a la discusión general sobre educación, y más específicamente para la $\mathrm{EDA}^{4}$, proviene de la economía y se refiere a la idea de productividad del individuo a partir de la adquisición y renovación de sus conocimientos.

É sob essa lógica que a trajetória recente da EPJA, no âmbito da educação formal e dentro do sistema oficial de ensino, vem se configurando a partir da década de 1990 no país.

É importante destacar que os antecedentes da EPJA no Chile têm sua gênese nos movimentos de educação popular que efervesceram a partir dos anos 50 em toda América Latina e que tinham, em linhas gerais, no seu escopo: mudança de uma realidade opressora; reconhecimento, valorização e emancipação dos diversos sujeitos individuais e coletivos; conscientizaçáo política e a educação de base como desenvolvimento comunitário e cultural. Embora interrompida pelo golpe militar ocorrido em 1973, a tradição da educação popular que fora desenvolvida nas décadas de 1960 e 1970 no país, quando houve uma vertiginosa expansão da EPJA, com maior ênfase no processo de alfabetização de adultos, se manteve impulsionada tanto pelos organismos internacionais quanto por diversos grupos políticos e organizaçóes de base, gerando uma corrente de educação popular articulada às lutas sociais da época. Desse período, como legado mais expoente, temos as ideias de Paulo Freire, que viveu no país de 1964 até 1969, e até os dias atuais representa a tradição intelectual e pedagógica desse movimento. Com o fim do período do golpe militar de 1973, a EPJA se limitou a processos de reposição de estudos no âmbito da educação formal.

As reformas neoliberais que foram iniciadas durante o regime militar de Augusto Pinochet (1973-1990) deixaram como herança o último ato de governo frente à transição democrática: a promulgação, em 10 de março de 1990, da Ley Orgánica Constitucional de Enseñanza (LOCE), conhecida também como "lei do último dia", que vislumbrando atender os interesses de uma nova estruturação produtiva que vinha se consolidando possibilitou mais claramente a oferta da EPJA pela iniciativa privada. 
En dos de sus artículos se hace referencia a la educación de adultos. El primero de ellos es el N.o 14, que señala: "El nivel de enseñanza básica regular tendrá una duración de ocho años y el nivel de enseñanza media regular tendrá una duración mínima de cuatro años. Tratándose de la enseñanza de adultos y de la especial o diferencial, el Presidente de la República, podrá autorizar modalidades de estudio de menor o mayor duración". Por su parte el artículo 15 de la mencionada ley señala: "La edad mínima para el ingreso a la enseñanza básica regular será de seis años e la edad máxima para el ingreso a la enseñanza media regular será de dieciocho años. Con todo, tales límites de edad podrán ser distintos tratándose de enseñaza de adultos y de la especial o diferencial, las que se especificarán por decreto supremo expedido a través del Ministerio de Educación Pública'” (COVARLÁN, 2010, p. 49)

O Chile experienciou, durante os anos 90, um vertiginoso processo de desenvolvimento econômico e de redução do desemprego, no qual o "empresariado passou a se ocupar da necessidade de elevaçáo da escolaridade da população, incluindo os adultos, de modo a ampliar a força de trabalho qualificada" (CATELLI, 2016, p. 97), visando a inserção laboral. Assim, os anos 90 representaram o ápice do desenvolvimento das políticas educativas voltadas para o alinhamento do país ao processo de expansão econômica. Segundo Vargas (2012, p. 1), "se privilegió la educación escolar básica y posteriormente la educación escolar secundaria, reduciéndose la educación de personas adultas a los programas de alfabetización y a confusos programas de formación laboral."

Dessa forma, a EPJA foi se delineando com base nos objetivos de incorporação de seus beneficiários ao mercado (CORVALÁN, 2007), sendo criados diversos programas educativos destinados à formação de mão de obra para o trabalho. Para atender à demanda emergente foram criados, nesse período o Programa de Educação Básica Anual (PEA), executado por instituiçóes públicas e privadas, que tinha como objetivo escolarizar adultos de 15 anos ou mais com a escolaridade incompleta; o Programa de Educação Fundamental de Capacitação Técnica Profissional (EFA), também realizado em instituições públicas e privadas, dirigido a adultos com 
15 anos ou mais e sem nenhuma escolaridade, que objetivava a formação de mão-de-obra em especialidades técnicas; o Programa de Educação Técnica Elementar de Adultos, destinado àqueles que possuíam do $6^{\circ}$ ao $8^{\circ}$ ano de estudos básicos e que integrava a formação técnico-profissional; o Programa de Educação Básica de Trabalhadores, para aqueles que possuíam alguma escolarização, e o Programa de Nivelação de Competências Básicas, para o mesmo público, e que preconizava a certificação básica escolar para a empregabilidade, este último desenvolvido em parceria com o Ministério do Trabalho e realizado por ONGs, associaçóes profissionais e outros organismos credenciados pelo Estado. (CHILE, 2009, p. 4, tradução nossa).

Constatamos que durante toda a década de 1990 e início dos anos 2000 o sistema educacional chileno pautou a EPJA prioritariamente em programas de formação de mão-de- obra para inserção no mundo do trabalho. Além disso, preservou o caráter assistencialista destinado à modalidade, com baixo grau de institucionalidade, reduzido a projetos de escolarização. Segundo Catelli Júnior (2016, p. 108), “a partir dos anos 2000, as políticas para a EDA no Chile tinham como foco a inserção da população menos escolarizada no mercado de trabalho".

Nas palavras de Acuńa (2015, p. 9), "A partir de 2000 se manifestó un esfuerzo mayor que buscó transformar la Educación de Jóvenes y Adultos, de acuerdo a las lógicas de la Reforma”, passando a configurar a modalidade não como uma resposta para as carências da educação básica, mas como parte das estratégias de educação voltada para a qualificação profissional. Em 2002, numa ação interministerial (ministérios da Educação, do Trabalho, da Economia e da Previdência Social) e com financiamento do Banco Mundial, foi implementado no país o Programa Chilecalifica, o qual, orientado prioritariamente para a educação de adultos, objetivava "establecer las bases para la implementación en Chile de un Sistema de Capacitación y Educación Permanente” (CHILE, 2009, p. 2), incorporando como carro-chefe de sua articulação e desenvolvimento a modalidade de ensino flexível que era destinada a EPJA. Essa modalidade, existente desde 1996, objetivava a reinserção escolar e o nivelamento de estudos às pessoas que náo tinham disponibilidade para frequentar a modalidade regular. 
O Chilecalifica contou com uma grande estrutura organizacional, a qual, como dito anteriormente, articulou diversos setores ministeriais e serviu como um projeto 'guarda- chuva' para abrigar dezenas de subprojetos. Além disso, para adequar a EPJA ao Chilecalifica, foi publicado pelo governo o Decreto Supremo de Educación no 239 de 15 de novembro de 2004, estabelecendo os objetivos fundamentais, os conteúdos mínimos obrigatórios para a educaçáo de adultos e fixando as normas gerais de sua aplicaçáo, o que se constituiu como um novo marco curricular para a EPJA no Chile. Apesar de a centralidade ser a modalidade flexível de ensino, o Ministério da Educação (MINEDUC) criou uma série de ações no âmbito do programa, tanto para o fortalecimento da modalidade regular quanto para a alfabetização e validaçáo de estudos, de sorte que se atendeu também à

Modalidad Regular Educación de Adultos, que tiene similitud en población objetivo (personas con 15 años cumplidos, jóvenes desertores recientes del sistema escolar) y objetivo (nivelar educación básica y educación media humanístico-científica) Campaña de Alfabetización Contigo Aprendo, que atiende población objetivo similar (personas jóvenes y adultas que no saben leer y escribir o que asistieron menos de cuatro ańos a la escuela) y cuya ejecución otorga un certificado de $4^{\circ}$ año de Educación Básica, válido para todos los efectos legales. Exámenes de validación de estudios o "exámenes libres", que atiende población objetivo similar (personas mayores de 15 años cuya situación les impida asistir a clases en un establecimiento educacional, o que no deseen hacerlo) y otorga una certificación de estudios válida para todos los efectos legales. (CHILE, 2009, p. 11)

No âmbito do Ministério do Desenvolvimento Social, por intermédio do Fondo de Solidaridad e Inversión Social (FOSIS), foi criado o Programa de Nivelación de Competencias Laborales (PNCL), tendo como beneficiárias pessoas entre 15 a 59 anos em situação de pobreza ou extrema pobreza, que poderiam nivelar seus estudos básicos. Pelo Ministério do Trabalho e executado pelo Servicio Nacional de Capacitación y Empleo 
(SENCE) foram criados programas especiais de treinamento para microempreendedores e subsídios para a empregabilidade de pessoas com baixa qualificação profissional.

Todos os programas e projetos que mencionamos passaram a constituir o Sistema de Formação Permanente, também denominado Sistema de Capacitação e Educação Permanente (SCEP), que tinha como metas:

- Desenvolver a educação de adultos na modalidade flexível para a educação básica e média;

- Articular a educação de adultos com a capacitação para o trabalho;

- Criar redes de articulação para a formação técnica;

- Formar docentes;

- Criar o Marco Nacional de Competências (MNC);

- Criar o Sistema de Certificação de Competências Laborais e de Empregabilidade (SCCLE);

- Elaborar o sistema de equivalências para os itinerários de formação técnica e capacitação;

- Oferecer o serviço de orientação vocacional e laboral e intermediação para o emprego.

Em síntese, todas as proposiçóes e metas do Chilecalifica (20022010) seguiram à risca as orientaçóes do Programa de Promoção da Reforma Educativa na América Latina e Caribe - e aí reside o sentido do financiamento pelo FMI - como o estímulo à administração por objetivos, à cultura da eficiência, à certificação e à demonstração de resultados. Conforme Ball (2002), tais orientaçôes procuram atender à performatividade escolar, o que é justificado por Acuña (2015, p.17) quando analisa que, nesse cenário, "la Educación de Adultos se vincula estrechamente con el ámbito productivo y laboral."

A análise do programa Chilecalifica realizada por Catelli (2016) aponta para uma série de dificuldades no cumprimento dos objetivos propostos. A principal delas o autor atribui à articulaçáo entre os ministérios, os quais, em meio a disputas orçamentárias, não conseguiram êxito em estruturar um sistema integrado, tornando os projetos independentes no âmbito de cada pasta. Catelli (2016, p.115) avalia que 
O processo de certificação de competências laborais atendeu de maneira mais imediata o déficit de mão de obra qualificada do ponto de vista técnico, uma vez que o Estado criou novos meios para a certificação profissional de trabalhadores. No entanto, a perspectiva que se constituiu acabou por se afastar do propósito original de uma educação permanente, na qual o indivíduo era visto como um todo, abrindo possibilidades para o seu desenvolvimento educacional tanto no campo profissional como no campo acadêmico.

Em 2006, houve novas discussóes em prol de reformas educacionais frente ao avanço da iniciativa privada e à baixa qualidade da educação no país. O movimento pingüim ${ }^{5}$ que, dentre outras reivindicaçóes, lutava contra o alargamento da rede privada subvencionada, por melhores condiçóes educacionais e com mais qualidade, acesso e permanência dos estudantes nas escolas públicas. Apesar de não ter colocado a EPJA em meio a suas pautas e reivindicações, gerou um debate geral sobre educação em toda a sociedade civil, forçando o governo a rediscutir a estrutura da educaçáo no país e a promulgar uma nova legislação educacional. Tal fato logrou reconhecimento à EPJA como uma modalidade de ensino da educaçáo básica na reformulação da LOCE; no entanto, a lei veio a ser revogada e substituída no primeiro governo da presidente Michele Bachelet pela Ley General de Educación (LGE) n. ${ }^{\circ}$ 20.370, de 12 de setembro de 2009, legislação educacional atualmente em vigor no país.

É importante destacar que durante o governo Ricardo Lagos (20002006) a promulgação da Lei n. ${ }^{\circ} 19.876$, de 7 de março de 2003, estabeleceu a obrigatoriedade e a gratuidade da educação básica, além de ampliar de oito para doze anos o processo de escolarização. E para atender às mudanças previstas na Lei, "la educación de adultos comienza a reestructurarse en virtud ya no de completar estudios inacabados sino de asegurar el derecho a la educación a todos." (WILLIAMSON; ACUÑA, 2013, p.7). Para esses autores, a modalidade

pasa a tener unidad, estructura, propósitos, curriculum propios. Se elaboró un nuevo Marco Curricular y Programas de Estudio, mejoró la subvención, perfeccionaron profesores y di- 
rectivos, diseñaron materiales, expandió el Programa Enlaces, mejoró el equipamiento e infraestructura. La EDA comenzó una nueva etapa de crecimiento, desarrollo y reconstrucción de identidad. (WILLIAMSON; ACUÑA, 2013, p. 4)

Do ponto de vista político-pedagógico, a EPJA passa a se configurar, em tese, náo como uma modalidade educativa remediadora, mas fundamental para se articular a outros setores, sobretudo em outras ofertas educativas nas quais as aprendizagens contínuas se alinham às necessidades básicas do público demandatário. Essa mudança, a priori, foi fundamental para sinalizar positivamente a reorganização da EPJA no país.

Por outro lado, embora a modalidade tenha alcançado algum reconhecimento, Zemelman (2009, p. 47) apresenta uma crítica quando afirma que a LGE apresentou "una ausencia de perspectiva para pensar a la Educación de Adultos desde las necesidades de construcción de un proyecto específico de país”, priorizando apenas a regulação de marcos curriculares e a autonomia das instituiçôes na elaboração dos seus planos de estudo, deixando de apresentar uma concepção clara sobre o entendimento do Estado em relação à EPJA. Esse fato se materializa com maior visibilidade na revogação do Decreto N. ${ }^{\circ}$ 239/2004 e a publicação do Decreto n.o 257/2009, em substituição ao anterior. Diante dessas ocorrências, observamos que as políticas educativas implementadas naquele país ao longo da última década cumpriram o objetivo principal da reorganização das políticas educacionais ao responderem às demandas do mundo da produção capitalista e da expansão do capital com ênfase nas noçôes de eficiência e eficácia. (BAZZO, 2006)

Atualmente, a EPJA é gerida, na estrutura do Ministerio de Educación (MINEDUC), pela Coordenação Nacional e Normalização de Estudos (CNNE), órgão vinculado a Divisão de Educação Geral (DEG) que tem como de sua competência a coordenaçáo dos processos educativos para todas as pessoas que se encontram fora do sistema regular de educação. Ao DEG compete a coordenação pedagógica e a gestão administrativa das diferentes modalidades educativas e dos processos de avaliação que estão voltados para complementação ou reconhecimento da trajetória educativa de crianças, jovens e adultos. 
A organização formal da EPJA dentro do sistema nacional de ensino chileno está organizada em duas frentes: a modalidade regular e a modalidade flexível, além dos programas de reinserçáo escolar, constituindo assim a educação de segunda oportunidade ${ }^{6}$ do país. A modalidade regular, considerada como a mais importante, divide-se em ensino básico e médio humanístico, científico ou profissional. Ela é desenvolvida no âmbito dos estabelecimentos educacionais públicos e privados reconhecidos oficialmente pelo Ministério da Educação, subdividindo-se em duas modalidades: na terceira jornada - quando funciona em classes noturnas - e nos Centros de Educação Integrada de Adultos (CEIA), que são instituiçôes públicas destinadas exclusivamente a adultos e oferecem simultaneamente a educação básica regular e o técnico profissional durante todo o dia. Já a modalidade flexível, de caráter semipresencial, é desenvolvida no âmbito de organizaçôes não governamentais (ONGs), universidades, igrejas, empresas, organismos técnicos e estabelecimentos escolares autorizados pelo Ministério da Educação, que participam de licitaçóes para oferecer esse tipo de ensino. É considerada flexível por ser desenvolvida em estruturas alternativas à escola, em diversos horários e em menor tempo, adequandose à disponibilidade de seus demandatários. Este tipo de oferta contempla os ensinos básico e médio.

Por meio de projetos de reinserção escolar, a CNNE também oferece alternativas específicas de oferta em recintos penais e de educação para crianças e adolescentes com idade entre 8 e 17 anos que se encontram fora do sistema regular de educação. Trata-se do desenvolvimento de estratégias de intervenção socioeducativas para população infantojuvenil em situação de exclusão e vulnerabilidade social. Esse tipo de oferta tem apoio e financiamento de instituiçóes públicas e privadas. Além dessas atribuiçốes, esse órgão dispóe ainda da validação de estudos, dirigido a pessoas maiores de 18 anos que se encontram fora do sistema escolar, tendo ou não alguma experiência educativa anterior, e que desejam certificaçáo fundamental e média. O processo de certificação se dá por avaliação nacional realizada anualmente.

Embora a diversificação na oferta educativa cumpra um importante papel para melhor atender às características da modalidade, permitindo maior flexibilidade de tempo, horários e locais de estudos, os dados do Encuesta Casen $2013^{7}$ apontam para um contingente de $45 \%$ da popula- 
ção maior de 20 anos que não terminaram seus estudos regulares (básico e secundário) e que se encontram fora da escola. A pesquisa de Castillo (2014, p. 8), que investigou a educação de adultos na perspectiva de seus beneficiários, retrata que,

Comparando los distintos programas de educación de adultos del sistema educacional chileno, se aprecia que en esta oferta educativa, de "segunda oportunidad", los aspectos transversales del currículo, relacionados con la importancia que esta política pública le asigna y declara a temas de inclusión y participación social, no se reflejan en las prácticas sociales de los estudiantes. Por el contrario, en términos generales, de los insumos que entrega esta investigación, se ratifica una baja participación social de los.

O estudo evidencia que apesar da diversificação da oferta, a forma como tem sido desenvolvida a EPJA no país não vem atendendo às necessidades e anseios de seu público, variável essa que, para o autor, tem justificado o desinteresse dos seus sujeitos de retornarem à escola: "El modelo o proyecto educativo de la escolarización de adultos, requiere que junto con

ha sufrido una involución conceptual de grandes proporciones. Cuando en el mundo se establece un consenso acerca de la importancia que los gobiernos avancen hacia el desarrollo de sistemas educativos que satisfagan la demanda de la educación y el aprendizaje permanentes de todas los grupos sociales, culturales y etarios «durante toda la vida», con la finalidad de crear capacidades en los ciudadanos para que participen activamen-

los contenidos curriculares clásicos, se acelere la incorporación de estrategias para la promoción de competencias sociales y cívicas." (CASTILLO, 2014, p. 8). (id.ib.) Os estudos de Acuña (2015 p. 61) reafirmam essa condição quando destacam que o principal motivo de deserção da modalidade é a falta de motivação, "en particular el no entender a las y los profesores cuando explicaban los contenidos y matérias." Em outras palavras, a EPJA que é oferecida no país não tem sido condizente com suas finalidades. Vargas (2013, p. 2) considera que ela capacidades en los ciudadanos para que participen activamen- 
te en la vida cívica, laboral y tecnológica (CEAAL-CREFAL, 2013; UNESCO-IUL, 2010), en Chile se ha restringido la educación de adultos a la "normalización de estudios" bajo las formas escolarizadas.

Contrapondo, Williamson e Acuña (2013, p. 7) defendem que as políticas educacionais recentes desenvolvidas do âmbito do MINEDUC têm refletido positivamente no desenvolvimento da EPJA no país, gerando

mejoramiento de la subvención, ampliación de oferta, mejoramiento de equipamiento y de infraestructura que ha ido generando una progresiva presencia como oferta y posibilidad para una cantidad importante de jóvenes y adultos.

Di Pierro (2008, p. 382) considera que "governos locais progressistas influenciados pelo paradigma da educação popular introduziram inovaçôes político-pedagógicas na EPJA que lhe conferiram maior flexibilidade e pertinência." A autora aponta o reflexo de tais processos e afirma que

as diferentes modalidades da oferta da EPJA estão plenamente inseridas nas instâncias oficiais da educação nacional, ainda que não ocupem uma posição de destaque na agenda de política educacional. A assimilação da EPJA pela política educativa chilena se deve ao fato de que ela cumpre não só a função de garantir o direito à educação pelo nivelamento de estudos, mas se propõe interferir na dinâmica do acesso ao trabalho e à renda, atuando também na qualificação profissional. (DI PIERRO, 2008, p. 382). (op.cit., p. 382)

Ainda que a conjuntura atual da EPJA no Chile reflita positivamente no protagonismo alcançado pelo país no cenário latino-americano, o processo de reivindicaçáo pela efetivação de políticas educacionais eficientes continua em pauta, objetivando, entre outros aspectos, "la definición desde el estado de provocar cambios curriculares y pedagógicos realizando importantes inversiones en la formación continua de los profesores y 
profesoras responsables por llevar a cabo el cambio." (WILLIAMSON; ACUÑA, 2013, p.14)

A ausência de uma concepção clara de EPJA é recorrente na fala dos pesquisadores que se dedicam ao tema no país (ESPINOSA; CASTILLO; GONZÁLEZ; SANTA CRUZ, 2014), (VARGAS, 2013). É importante salientar que a pesquisa acadêmica sobre a EPJA é incipiente e mantém uma relação direta com a pouca relevância com que tem sido tratada a modalidade enquanto política de Estado. A Universidad de Playa Ancha (UPLA) tem sido a mais importante instituição de fomento, ensino e pesquisa sobre EPJA no país, além de ser a principal interlocutora com o MINEDUC. Outras IES como a Universidad de La Frontera (UFRO) e a Universidad de Valparaiso (UV) também têm desenvolvido, nos últimos anos, algumas atividades voltadas para EPJA.

No sentido de ampliar as discussóes sobre a modalidade, vem ocorrendo naquele país, desde o ano de 2012, o Seminario Internacional Educación de Jóvenes y Adultos. O evento, de caráter anual, é promovido pelo Programa Disciplinário de Educação de Jovens e Adultos da Universidad de Playa Ancha (UPLA), situada em Valparaíso, e tem parceria com IES da região, além de contar com o apoio de outros órgãos como (CREFAL) e Ministério da Educação.

Os seminários proporcionam discussões em torno de questôes como diversidade e interculturalidade, relaçôes entre educação e trabalho, redes pedagógicas, formação de professores e novas experiências didáticas em EPJA e têm fomentado no país importantes debates e proposiçôes na área. $\mathrm{Na}$ última edição do encontro, em 2015, onde estivemos na condição de observador convidado, pudemos acompanhar as principais tendências e tensôes para essa área de ensino no país. A partir da realização de diversos grupos de trabalho, divididos por eixos temáticos mais relevantes, para se traçar o diagnóstico atual da EPJA, foi possível materializar as principais demandas que têm emergido no cenário político, pedagógico e educativo que o país vive hoje.

O grupo de trabalho 'Diagnostico, propuestas y proyecciones en la Educación de Jóvenes y Adultos', coordenado pela Professora Maria Clara di Pierro, da Universidade de Sáo Paulo, produziu ao final do encontro um relatório que talvez seja o que melhor situe o tempo presente da EPJA no Chile, hoje. Apesar de alguns avanços, as demandas reivindicatórias 
comuns na área e que estão presentes na maior parte dos países latinoamericanos como baixa visibilidade, recursos escassos, descontextualização curricular, ausência de metodologias apropriadas e necessidades formativas para atuar no campo, não fogem à realidade presente no país.

$\mathrm{O}$ trabalho das pesquisadoras e atualmente coordenadoras nacionais da EPJA no Chile, professoras Maria Izabel Infante e María Eugenia Letelier, que apresentaram durante o evento uma análise desde a perspectiva institucional/ministerial até as exigências atuais para a EPJA, também pode ser tomada inicialmente como norteamento para se (re)pensar algumas condições para essa modalidade de ensino. Nas exposiçóes ficou evidenciada a necessidade de (re)pensar o modelo atual da EPJA, o qual, na atualidade, está descrito como mais centrado na aprendizagem da educação formal, e de alternância para um conjunto maior de objetivos de aprendizagem inseridos em um contexto educativo mais amplo, gerando uma oferta "que permita avanzar según las posibilidades y expectativas de la población, a la vez que se requiere de una inyección de recursos financieros que permita poner en acción la propuesta tanto para infraestructura, capacitaciones, materiales, entre otros" ${ }^{\prime \prime}$, o que permitiria, portanto, a criação de uma cultura do direito à educação ao longo da vida e as condiçóes políticas e pedagógicas efetivas para esse fim.

\section{Algumas consideraçóes (in) conclusivas}

O exposto até aqui nos permite afirmar que situar a EPJA dentro do sistema educacional chileno é uma tarefa complexa e exige uma análise crítica sobre a educação como um todo. Ainda que o Estado chileno garanta o direito fundamental de educação a todas as pessoas, o sistema de subvenção criou um modelo de financiamento da educação pública altamente regulado pelo mercado e pela iniciativa privada. Dessa forma, a centralidade das políticas públicas de educação no Chile está no atendimento prioritário a cidadáos que se encontram matriculados em instituiçôes de ensino onde existe maior investimento do setor público, o que coloca a EPJA em um plano secundário, claramente à margem institucional. Não é à toa que o perigoso e pejorativo termo 'segunda oportunidade' assumiu lugar comum nas discussóes sobre esses tipos de oferta de ensino para EPJA. 
A sociedade chilena convive com as normas do mercado em diversos setores. O sistema educativo é apenas mais uma das esferas institucionais na qual o lucro se configura como a principal bandeira de desenvolvimento do país. Assim, não é difícil compreender a forte ideia de vantagem econômica que se tem em relação à educação. Se a EPJA não atende aos negócios da educação, tampouco desperta interesse de seu formulador e operador primário: o Estado.

No exercício de apresentar a trajetória recente da EPJA no país, cumpre ainda destacar que as informaçóes sobre essa modalidade educativa no Chile são escassas. A maior parte dos documentos que circulam sobre ela foi elaborada no âmbito institucional do governo, com pouca produção científica e acadêmica do próprio país. Os valores destinados ao financiamento público para a modalidade também não estão acessíveis à sociedade, pois nem mesmo no portal Directorio Transparência, site oficial de informaçôes sobre os gastos públicos do país, é possível cotejar dados sobre os valores destinados à educação de jovens e adultos.

Há, na realidade, um enorme esforço para a manutenção da estrutura de mercado existente no sistema educacional privado que recebe subsídio público no país. Igrejas, médios e grandes empresários, inclusive agentes econômicos internacionais, as chamadas holdings, compóe uma parcela institucional que resiste a qualquer mudança ao formato mercantil da oferta. Em 2009, por ocasião da Semana de Acción Mundial por el Derecho a la Educación, o Fórum Nacional Educação de Qualidade para Todos, organismo que agrega diversos seguimentos da sociedade civil, reivindicou no documento Propuestas para Fortalecer las Politicas Educativas dirigidas a Jóvenes y Adultos en Chile que os princípios econômicos, naturalizados no inconsciente coletivo de uma sociedade que se acostumou a pensar a educação com elemento da economia nacional, não podem se sobrepor à defesa da educação gratuita.

O 'inconsciente coletivo' mencionado nesse texto está relacionado à ausência de um pensamento crítico que contrarie o processo de mercantilização da educação pública e o projeto que foi se constituindo em torno dela ao longo das últimas três décadas. Segundo Diaz (2015, p. 43), trata-se de um processo "naturalizado pelo que Burton designa como a 'representação limitada', caracterizada pela ausência de qualquer contra- 
peso ao paradigma neoliberal hegemônico e a consequente fraqueza dos movimentos sociais."

Durante o tempo de permanência no Chile, entre os meses de maio a julho de 2016, período inicial de construção deste texto, em entrevista com Maria Isabel Infante, atual Coordenadora Nacional de Educação de Adultos (CNEA), que também esteve à frente desse órgão no primeiro governo da presidente Michelle Bachelet (2006-2010), relatou-nos que em sua visão institucional a EPJA ainda náo alcançou um elevado grau de desenvolvimento no país. Embora ela, como gestora, reconheça os avanços que têm sido empreendidos no sentido de retomar as bases desenvolvidas em sua primeira gestão frente à CNEA, quando foi implantado o Chilecalifica, houve descontinuidade no governo de Sebastián Piñera (2010-2014), pois esse programa náo ocupou posiçáo estratégica dentro da estrutura educacional do país.

Para a gestora, quanto às pessoas analfabetas no país, cerca de meio milhão, e os cinco milhões que não concluíram os estudos, elas representam um número relativamente pequeno frente a outros países da América Latina. Em nosso entendimento, essa posição busca justificar a ideia de que, devido ao baixo número de demandatários da EPJA no país, não sejam necessários empreendimentos urgentes para a modalidade. Como perspectiva até 2018, ano de encerramento da gestão do atual governo, era previsto um investimento de nove milhôes de pesos chilenos na EPJA, a transformação de 40 dos atuais 399 Centros Integrados de Educación de Adultos (CEIAS) em centros de educação permanente, o aumento da modalidade flexível de ensino e dos programas de nivelação de estudos e a criação de um sistema de educação permanente no país. No âmbito pedagógico, está em discussão, entre um grupo ministerial e especialistas de algumas universidades, a criação de um novo marco curricular para a EPJA, além do desenvolvimento de cursos voltados para a formação dos professores que atuam na modalidade, como o que atualmente é gerido pelas Universidades de Playa Ancha e a Católica de Valparaíso, que trata da avaliação da modalidade em todo país.

Os poucos pesquisadores da área de EPJA no Chile consideram, entretanto, que as açóes que vêm sendo desenvolvidas atualmente pelo MINEDUC são vazias e desarticuladas, reforçando a condição de secundaridade da modalidade dentro de uma proposta de oferta que contemple 
os acordos internacionais assumidos pelo país. Também consideram que nos últimos anos a EPJA no Chile vem sofrendo uma inversão conceitual de grandes proporçôes, com maior ênfase no período de governo do presidente Sebastián Piñera, o que tem provocado uma política de descontinuidade por parte do Estado.

Mesmo no atual governo, a compreensão da EPJA como 'normalização de estudos' continua presente nos documentos institucionais, se configurando como um conceito restrito e discriminatório que implica, entre outros fatores, na invisibilidade dos centros de educaçáo de adultos, ausência de formação de professores para esse campo da educação, além de infraestrutura inadequada e baixa subvenção escolar. Sendo um dos signatários dos compromissos assumidos na CONFINTEA, o país não tem colocado em prática os acordos internacionais, o que se revela na ausência de políticas públicas que estejam voltadas para a EPJA.

Para além da reversão do cenário periférico que a EPJA ocupa nas políticas educacionais do país, é consenso entre os autores que a discutem que a modalidade precisa ser redimensionada com uma mudança conceitual radical do sistema educacional como um todo, pela qual se reconheça, primeiramente, a educação como um direito humano e um bem público, fazendo com que o Estado venha a cumprir sua obrigação de garanti-la por meio de instituiçóes de ensino de qualidade, não deixando espaço para aqueles que possam conduzí-la com base em fórmulas neoliberais, reduzindo gastos do governo e passando à iniciativa privada a função de 'educar para a vida' com base no mercado.

Nesse sentido, em outubro de 2014, por meio de representação política do deputado Rodrigo González, foi encaminhado à Comissão Mista de Educação e Fazenda um documento formulado pela rede de universidades que apoiam a EPJA no país. Entre as reivindicaçóes estava presente uma nova sistematização política para a modalidade e novas formas de financiamento, requerendo-se, portanto, maior compromisso do Estado na articulação de uma política pública que cumpra os desafios da modalidade no país. Para os formuladores desse documento, o desenvolvimento da EPJA no sistema educacional chileno necessita ser redimensionado com vistas a responder aos desafios da sociedade do conhecimento, na direçáo de promover a sustentação do processo de participação social e consolidação da democracia. E, para além disso, faz-se necessário que o Estado 
construa uma política pública de financiamento permanente e amplie a participação de atores institucionais (ONGs, universidades, sociedade civil) nas discussóes sobre a área, de maneira que a sistematização de experiências educativas venha a contribuir com estratégias que, de fato, atendam às necessidades das pessoas que demandam essa modalidade de educação.

De todo o exposto, as inferências dos dados produzidos sinalizam que no processo de traduzir, nacionalizar e se adequar às orientaçóes políticas destinadas a EPJA - defendidas ao longo dos anos por movimentos internacionais, sobretudo aquelas acordadas desde a Declaração de Hamburgo, passando pelas CONFINTEAS, da qual o Chile é signatário -, os compromissos ainda não foram totalmente assumidos na agenda educativa do país.

Assim, a perspectiva certificadora da EPJA acompanha as bases ideológicas da política neoliberal assumida pelo Estado. Programas de abrangência nacional voltados para a elevação da escolaridade de jovens e adultos e integração ao mercado de trabalho, a exemplo do Chilecalifica, dão uma ideia da concepção de EPJA que foi construída. Dessa forma, o entendimento de que ela deve cumprir a finalidade de integrar seus sujeitos ao mundo do trabalho e garantir a empregabilidade, ainda que nos últimos anos essa perspectiva venha se modificando, permanece muito forte.

\section{Notas}

1 Utilizamos a palavra regiáo como categoria geográfica de análise que tem por finalidade nomear as diferentes divisōes de um espaço geográfico. (LENCIONI, 1999)

2 Cálculo que leva em consideração, para o financiamento da educação, a quantidade de alunos atendidos pelos municípios. (SCHNEIDER, 2015)

3 Cada pai ou responsável recebe do governo um cupom, que pode ser utilizado para pagar parcial ou integralmente a mensalidade de qualquer escola que seja elegível para receber esse subsídio. Para ser elegível ao recebimento do benefício, as escolas credenciadas devem atender as exigências do ministério da educação.

4 O termo Educação de Adultos (EDA) foi a nomenclatura oficial empregada pelo Ministério da Educaçáo do Chile para a modalidade até o ano de 2013. A partir dessa data passou a chamar-se Educação de Pessoas Jovens e Adultas (EPJA).

5 Movimento massivo de estudantes secundários que alcançou grande visibilidade internacional, forçando o governo a reeditar a legislação educacional, particularmente a Lei Orgânica Constitucional de Ensino (LOCE) promulgada no final da década de 90 durante o período da ditadura militar chilena. $\mathrm{O}$ nome pinguim se refere à caracterização da roupa que os estudantes utilizam nos protestos: branca e preta.

6 O termo 'segunda oportunidade' é amplamente utilizado pelo MINEDUC para referir-se aos 
programas destinados à Educação de Adultos.

7 "La Encuesta de Caracterización Socioeconómica Nacional (Casen) del Ministerio de Desarrollo Social es una encuesta a hogares, de carácter multipropósito, es decir, que abarca diversos temas como educación, trabajo, ingresos, salud, entre otros; además es una encuesta transversal, por lo tanto, incluye a todo el espectro de la población del país." (CHILE. Ministério do Planejamento do Governo do Chile. Disponível em: <http://encuestacasen.cl> Acesso em: 15 fev. 2019.

8 Relatório produzido e apresentado pelo professor Claudio Navarrete Hidalgo, coordenador do grupo de trabalho (GT) Exigencias Actuales para el Curriculum en la Educación Jóvenes y Adultos, a partir da exposição dos representantes ministeriais durante o Terceiro Seminário de Educação de Jovens e Adultos realizado em Valparaíso, Chile, entre os dias 19 e 20 de novembro de 2015.

\section{Referências}

ACUÑA. Violeta, R. C. Experiencia del Diplomado de Educación de Adultos en la Universidad de Playa Ancha, Chile. Decisio, México v. 42, p. 45-49, 2015.

BALL, S. Reformar escolas/reformar professores e os terrores da performatividade. Revista Portuguesa de Educação, Braga, v. 15, n. 2, p. 3-23, 2002. 15(2), pp. 03-23.

BAZZO, V. L. As consequências do processo de reestruturação do Estado Brasileiro sobre a formação dos professores da Educação Básica: algumas reflexôes. In: PERONI, V. M. V.; PEGORARO, L.; COSTA, A. C. (org.). Dilemas da educação brasileira em tempos de globalização neoliberal: entre o público e o privado. Porto Alegre: Editora da UFRGS, 2006. Nacional, 1972.

BRITO, Vera Lúcia Alves de. O público, o privado e as políticas educacionais. In: OLIVEIRA, Dalila Andrade; DUARTE, Maria R. T. (org.). Politica e trabalho na escola: administração dos sistemas públicos de educação básica. Belo Horizonte: Autêntica, 2001.

CASASSUS, J. A reforma educacional na América Latina no contexto de globalização. Caderno de Pesquisa, Sáo Paulo: Autores Associados, n. 144, p. 07-28, nov. 2001.

CASTILLO, Dante. Educación de adultos y participación social en chile: la perspectiva de los beneficiarios. Anais do Tercer Congreso Interdisciplinario de Investigación en Educación. Santiago, Chile. 2014. Disponível em <http://www.ciee.cl> Acesso em 26 de agosto de 2016.

CATELLI JÚNIOR, Roberto. Políticas de Certificação por meio de exames nacionais para a Educação de Jovens e Adultos: um estudo comparado entre Brasil, Chile e México. Tese (Doutorado - Programa de Pós-Graduação em Educação) FE/USP, 2016.

CHILE. Ley Orgánica Constitucional de Enseñanza. N.o 18.962. Santiago, 10 de março de 1990. 
CHILE. Ministerio de la Educación. Decreto Supremo de Educación, No 239 del año 2004 (Marco Curricular de la Educación de Adultos) Disponível em: <https://www. ayudamineduc.cl/ Estatico/docs/informacion/info_guia/guia_adul.pdf> Acesso em: 26 dez. 2015.

CHILE. Ministerio de Educación. Ministerio de Economía. Ministerio del Trabajo y Previsión Social. Resumen Ejecutivo: Evaluación en Profundidad Programa Chilecalifica. Santiago de Chile: Santiago Consultores Associados, 2009. Disponível em: <http://www.sence.cl/601/articles-3078_archivo_011.pdf> Acesso em: 26 nov. 2016.

CORVALÁN, Javier. La educación de mercado en Chile y su propuesta de superación, Cuaderno de Educación, No 66, junio de 2010.

CORVALÁN, Javier. El campo educativo chileno. Informe de circulación restringida. Proyecto Equidad para la Acción. Santiago de Chile: CIDE, 2007.

CORVALÁN, Javier Situación presente de la educación de personas jóvenes y adultas en Chile. México: CREFAL, 2008.

DI PIERRO, Maria C. Educação de Jovens e Adultos na América Latina e Caribe: Trajetória Recente. Cadernos de Pesquisa, v. 38, n. 134, maio/ago. 2008.

DI PIERRO, Maria C.; JOIA, Orlando; RIBEIRO, Vera M. Visões da Educação de Jovens e Adultos no Brasil. Cadernos Cedes, ano XXI, no 55, novembro/2001.

DÍAZ, Sebastián D. Nova institucionalidade da educação pública no Chile: Debates, análises e propostas. In: GOUVEIA, Andreia Barbosa et al.(org.). Brasil e Chile: Diálogos (im)pertinentes. Curitiba, Appris, 2015.

ESPINOZA DÍAZ, O., CASTILLO, D., GONZÁLEZ FEIGEHEN L., SANTA CRUZ, J. Educación de adultos e inclusión social en Chile. Psicoperspectivas, v.13 n.3, p. 69-81, 2014. Disponível em: <http://www.psicoperspectivas.cl>. Acesso em: 14 jan. 2017

KRAWCZYK, Nora Rut; VIEIRA, Vera Lúcia. Homogeneidade e heterogeneidade nos sistemas educacionais: Argentina, Brasil, Chile e México. Cadernos de Pesquisa, São Paulo, v. 36, n. 129, p. 673-704, set./dez. 2006.

LENCIONI, Sandra. Região e geografia. São Paulo: Edusp, 1999.

MARQUEZ, Diego M. Educación Comparada: teoria y metodologia. Buenos Aires: Editorial El Ateneu, 1972.

NÓVOA, António. Modèles d'analyse en Éducation Comparée: Le Champ et la Carte. Les Sciences de l'Éducation pour l'ère nouvelle, n. 2/3, p. 9-61, 1995. 
SCHNEIDER, Gabriela. Centralização, Descentralização ou Descentralização: um olhar sobre a realidade brasileira e chilena. In: GOUVEIA, Andreia Barbosa et al. (org.). Brasile Chile: Diálogos (im)pertinentes. Curitiba, Appris, 2015.

TORRES, Carlos A. Política para educação de adultos e globalização. Currículo sem Fronteiras, v.3, n.2, pp.60-69, Jul/Dez 2001.

TORRES, Carlos Alberto. Estado, polítcas públicas e educação de adultos. In: GADOTTI, Moacir \& ROMÃO José Eustáquio. (org) Educação de Jovens e Adultos: teoria prática e 11 propostas. - 3a ed. - São Paulo: Cortez: Instituto Paulo Freire, 2003.

UNESCO. Relatório Global Sobre Aprendizagem e Educação de Adultos. Brasília: UNESCO, 2010.

UNESCO. Relatório Global Sobre Aprendizagem e Educação de Adultos. Brasília: UNESCO, 2012.

VARGAS, Jorge Osório. La educación de personas adultas como "inversión en ciudadanía" $y$ "bienestar en común": hacia otro paradigma de desarrollo educativo. Disponível em: <http://merlinescas.blogspot.com.br/2012/05/la-educacion-de-personas-adultas-como. html> Acesso em: 7 ago. 2017.

VARGAS. Desafíos docentes en la Educación de Jóvenes y Adultos en Chile: hacia una agenda de conversaciones para el diseño e implementación de nuevas políticas. Revista Temas de Educación, n. 19, v. 1, 2013.

WILLIAMSON, Guillermo C.; ACUÑA, Violeta C. Profesores y Profesoras que se Perfeccionan en la Educación de Adultos de la macro Zona Sur del Chile. Revista Educación y Humanidades, Año 3 v. especial, 2013.

ZEMELMAN, Hugo. Sobre políticas y educación de adultos: necesidad de un enfoque. Revista Interamericana de Educación de Adultos, v. 31, n. 2, p. 49-62 jul./dez. 2009. Disponível em: http:/www.crefal.edu.mx/rieda/index.php?option=com_content\&view $=$ article $\&$ id $=196 \&$ Itemid $=179$ Acesso em: 11 set. 2018 .

Recebido em 26 fev. 2018 / Aprovado em 2 jan. 2019

Para referenciar este texto:

CUNHA JÚNIOR, A. S.; SOARES, L. J. G. COLLADO, V. R. A. A trajetória recente da educação de pessoas jovens e adultas no Chile: inferências de um estudo comparado. EccoS - Revista Científica, São Paulo, n. 48, p. 385-408. jan./mar. 2019. Disponível em: <https://doi.org/I0.5585/EccoS.n48.8396>. 